\title{
To Have What It Takes: A Multi-Tiered Psychological Resource Model of First-Generation College Student Success
}

\author{
Leehu Zysberg1, Karla Verlinden², Cora Zingerle ${ }^{2}$ \\ ${ }^{1}$ Gordon College of Education, Haifa, Israel \\ ${ }^{2}$ Katholische Hochschule Nordrhein-Westfalen, Koeln, Germany \\ Email: leehuzysberg@yahoo.com
}

How to cite this paper: Zysberg, L., Verlinden, K., \& Zingerle, C. (2021). To Have What It Takes: A Multi-Tiered Psychological Resource Model of First-Generation College Student Success. Psychology, 12, 15611574.

https://doi.org/10.4236/psych.2021.1210098

Received: September 13, 2021

Accepted: October 22, 2021

Published: October 25, 2021

Copyright $\odot 2021$ by author(s) and Scientific Research Publishing Inc.

This work is licensed under the Creative

Commons Attribution International

License (CC BY 4.0).

http://creativecommons.org/licenses/by/4.0/

\section{(c) (i) Open Access}

\begin{abstract}
First generation students typically show more difficulties adapting to academic studies and lower attainments than their counterparts hailing from academic families. While the literature offers insights into factors associated with these outcomes, there is little understanding of the processes underlying this phenomenon. This study presented and tested a model combining demographic, individual level and interpersonal level resources, all drawn from the field of positive psychology, to account for first generation and non-first generation students' academic attainment in college. A sample of 199 students attending college in Germany, 38\% of whom reported being first generation students, filled out a demographic questionnaire, including a report of the GPA, as well as measures of grit, self-efficacy, emotional intelligence and sense of coherence and social support. The results support a double mediation model that suggests that personal resources and social support mediate the association between background variables (gender), being a first-generation student and college GPA. The results are discussed in the context of positive psychology theories and our existing knowledge of the challenges first generation students encounter in academia.
\end{abstract}

\section{Keywords}

First Generation Students, Sense of Coherence, Self-Efficacy, Emotional Intelligence, Grit, Social Support, Academic Achievement

\section{Introduction}

The importance of academic education as means of social mobility, and social 
justice, has received significant attention in educational and sociological settings (e.g.: Stuart, 2012). Attaining academic degrees has been consistently associated with improved socio-economic status, and even better health status (Azhar et al., 2014; Fiscella, \& Kitzman, 2009). Academic education is often regarded as a major tool for socio-economic mobility and can therefore serve and be of special importance to students who are the first in their families to pursue academic training (Haveman and Smeeding, 2006). That being said it is also noted in the literature that first generation students (FGS), might negotiate more challenges and hardships on their way to attaining academic education compared with students coming from families that are academically established (Schwartz et al., 2018). It seems then that the same students who would benefit the most from academic education, and will take part in mobilizing underprivileged populations, are the ones who meet higher levels of difficulties and are at risk of dropout, compared with their peers hailing from academic families (Aymans \& Kauffeld, 2015). It is therefore of added value to examine the nature of challenges FGS meet while exploring the personal resources that may play a role in their academic attainment.

To address the issues above, this study presented and tested a multi-tiered resource-based model accounting for FGS performance in college, relying on a conceptual framework borrowed from the field of positive psychology.

\section{First Generation Students}

Since the 1990s, studies present a consistent and somewhat dismaying picture for FGS in academia: They arrive in college with less knowledge about academic education, and the academic system, report receiving less support from their families, and report experiencing more stress regarding their studies (Pascarella et al., 2004; York-Anderson \& Bowman, 1991). No wonder then that FGS also experience a starker gap between their high-school learning experience and their college experience. They also attain lower GPA than their peers hailing from academic families (Palbusa \& Gauvain, 2017; Strayhorn, 2007).

Beyond social and educational factors as mentioned above, other studies examined the role of individual characteristics and resources that may underlie FGS performance in college. One of the popular factors studied is self-efficacy (or the belief in one's own ability to successfully meet requirements or fulfil a task), and the evidence indeed suggest that FGS show lower levels of self-efficacy in general and academic self efficacy in particular (e.g.: Ramos-Sánchez \& Nichols, 2007). Other studies looked at additional personal factors such as locus of control, self-esteem, and more, all showing evidence of being lower with FGS, compared to their peers (e.g.: Aspelmeier et al., 2012). While the evidence is there for a broad array of factors, an organizing framework or model that will offer insight into underlying processes is still lacking. We propose using the general framework of positive psychology as a guide to the formation of a preliminary model of FGS resources that allow the students to effectively (or less effectively) meet academic demands and attain academic success. 


\section{The Study Model}

Positive psychology has presented, about 40 years ago an alternative to the clinical approach that dominated psychology until that time: It suggested that instead of focusing on pathology and prevention, at least certain fields touching everyday psychological function (e.g.: work, studies, etc.) need to focus on the salutogenic aspects of human functioning (Antonovsky, 1996). In the passing decades research has focused on specific concepts and factors associated with personal resources that serve as potential for effective coping and flourishing in challenging circumstances (Ouweneel et al., 2011), and some even suggest stress-related growth (Park, Cohen, \& Murch, 1996). While some evidence does point to the relevance of major concepts borrowed from positive psychology in FGS college performance (e.g.: the study of resilience and emotional intelligence in FGS versus non FGS, see: Alvarado et al., 2017), there is currently no published comprehensive model examining the roles of positive psychology concepts alongside personal background variables and interpersonal factors, which is the goal of the current study.

\section{The Model Components}

Demographics: Studies have pointed out a few demographics that may play a pivotal role in the way we manage and mobilize resources when coping with challenges: Gender has been one of the most frequently studied factors in accessing and utilizing positive psychology resources such as Emotional intelligence, resilience, hope etc. (Fischer et al., 2018; Le Masson et al., 2016). Education and income level (often conceptualized as socio economic status, SES) have often been considered intervening factors (Reynolds \& Cruise, 2020) and were thus measured and controlled for in our study, as well as age.

The following concepts are factors borrowed from the field of positive psychology, often associated in existing research and theory with daily life outcomes in work or educational settings and were thus at the focus of the present study:

Grit: Grit encompasses the ability of an individual to pursue long-term goals with enthusiasm and persistence. This non-cognitive competence is related lifetime educational attainment (Duckworth \& Quinn, 2009) and with professional success (Vallerand, Houlfort, \& Forest, 2014).

Self-Efficacy $(S E)$ : Going back much farther than the appearance of positive psychology the concept was nonetheless embraced by the field. The concept pertains to the extent to which individuals perceive themselves as capable of meeting a challenge or successfully completing a task (Artino, 2012). People who have a high self-efficacy are more likely to enter challenging life situations than people with a low self-efficacy experience. In addition, studies show that students with high self-efficacy are less likely to drop out of their studies and identify more with their university than students with low self-efficacy (Ramos-Sánchez \& Nichsols, 2007). In addition, further studies underline that self-efficacy is linked to the performance of cognitive tasks and the problem-solving process during the assess- 
ment process and that as a result better grades can usually be achieved (Agustiani, Cahyad, \& Musa, 2016; Bouffard-Bouchard, 1990; Niemivirta \& Tapola, 2007; Multon, Brown, \& Lent, 1991; Ouweneel et al., 2011, 2013).

Sense of Coherence: Sense of coherence (SOC) is defined as a global orientation that expresses the extent to which a persistent yet dynamic sense of trust can be felt in terms of the influence that one's own behaviour has on the environment in that the individual perceives it as structured, predictable and explainable (Antonovsky, 1996). A high sense of coherence is in proportion to a high degree of resilience (Shankland et al., 2019) and to educational success (Salamonson et al., 2016).

Emotional Intelligence: Emotional Intelligence (EI), as the ability to (correctly) perceive, understand and influence one's own and others' feelings, is associated both with resilience (Armstrong et al., 2011) and educational success (MacCann et al., 2011; Thomas, Cassady, \& Heller, 2017). EI is association with positive educational outcomes, among others is attributed to individuals' higher ability of effectively managing emotions, and harnessing them to facilitate problem solving as well as adaptive behaviors in challenging conditions.

While positive psychology tends to focus on personal resources primarily, it does suggest other resources, namely social and interpersonal resources are at play in our adaptation in unexpected circumstances. Of all these resources social support is perhaps the most studied and validated.

Social Support. Social support is a concept which is highly relevant to almost any type of effective coping with challenges and therefore people with a high experience of social support can be considered particularly resilient (Reinelt et al., 2015). It represents the extent to which individuals perceive meaningful others' availability to them, and their willingness and ability to meet their expectations and needs. The literature typically differentiates between at least two types of support-socio-emotional and instrumental (Yuh \& Choi, 2017).

Based on the above literature we may draw a process line or a model of resources anchored in positive psychology theory accounting for FGS academic attainment in College. We start with demographics, which associate with the availability of personal resources, which in turn associate with recruiting social support, finally correlating with academic achievement. The model is graphically presented in Figure 1.

\section{Method}

\subsection{Settings and Sample}

Participants included 199 undergraduate students enrolled in a public, small sized university in Midwest Germany. The area is a heavily urbanized and industrialized area of the country which is experiencing growth and development. The area is diverse in terms of religious and ethnic composition of the population but the campus from which the sample was taken is predominantly Christian.

The participants' age ranged $19-42($ mean $=23.22$; sd $=3.56)$. Eighty-five 


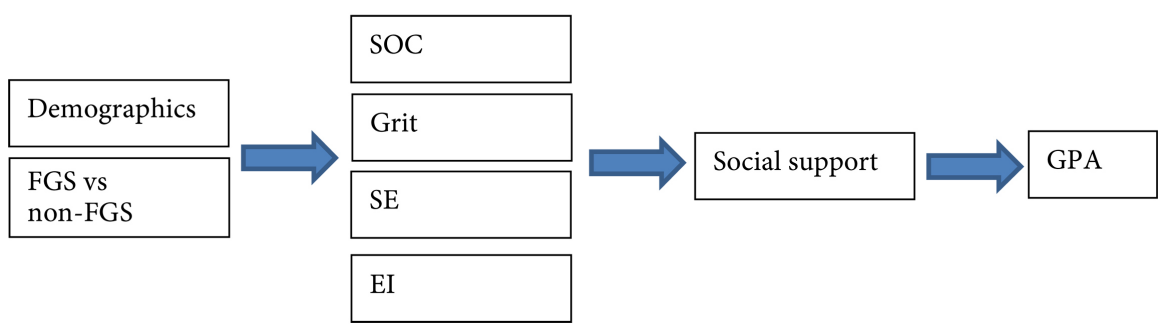

Figure 1. The proposed model.

percent were women, and the rest were men. Almost 92\% reported their religion as Christian, 3.5\% identified as Muslims and the remaining 4.5\% did not report their religious affiliation.

The participants were recruited in lectures which are obligatory for all students in their third and fifth semester. The data collection took place in the mornings under the same instructor. The participants voluntarily agreed to fill out an online-based survey.

\subsection{Measures}

Data collection was carried out using standardized, validated self report measures of each of the variables appearing in the study model:

1) Academic attainment. Academic achievements were assessed by self-reported grand point average (GPA). While not necessarily a sensitive indicator of academic performance, it is nonetheless a popular measure used in various settings, including academic research, candidate selection and more (Nasir \& Ikbal, 2019).

2) Social Support. The questionnaire includes four own created items, because no questionnaire was available for the specific sample. Typically, social support scales do not capture individual levels of support at college. Therefore, a separate questionnaire was developed, which scored 0.8 on the parallel test reliability test. It measures the experience of the social support within the categories: family, friends, fellow students and university/college. Sample item: "I get the help that I need from my fellow students."

The answers were given with the help of a 5 -stage Likert-scale $(1=$ strongly agree; 5 = strongly disagree). The sum of the given answers gets divided by the number of questions (four). A low score (1) equates a high level of experienced social support on the contrary a high score (5) corresponds a low level of social support.

3) Sense of Coherence. The Leipzig Short Scale (SOC-L9), based on the SOC29 Scale, developed by Antonovsky (1996) consists of nine items and measures the constructs comprehensibility, manageability and meaningfulness in the subjective assessment of the participant. Sample item: "If you think about life, you often: [Answer options from:] (1) have the feeling that it is wonderful to live; to (7) wonder why you are alive anyway". "In the empirical studies, for the total scale (SOC-29) reported predominantly good to very good internal consistencies 
(Cronbach's Alpha between 0.82 and 0.95" (Schumacher et al., 2000). The answers get summed up so $\min =9$ and $\max =63$. The lower the score the better the sense of coherence and the other way round.

4) Grit. The questionnaire includes twelve items and measures the "individual's capacity to persistently and enthusiastically pursue long-term goals. This non-cognitive skill is an important prerequisite for educational and vocational success" (Fleckenstein et al., 2014). Fleckenstein et al. translated the English scale [by Duckworth et al. (2007)] and tested it on a sample of $\mathrm{N}=173$ pre-service teachers. Sample item: "I often set a goal but later choose to pursue a different one." The answers were given with the help of a 5-stage Likert-scale ( $1=$ strongly agree; $5=$ strongly disagree). Reverse score for questions 7 to 12 . The sum of the given answers gets divided by the number of questions (twelve). A low score (1) equates a low level of grit on the contrary a high score (5) corresponds a very high level of grit. The average in Germany is 3.81 (Fleckenstein et al., 2014).

5) Self-Efficacy. The SEW questionnaire, developed by Schwarzer \& Jerusalem (1999) includes ten items and measures "one's perceived competence to cope with a broad range of stressful or challenging demands" (Schwarzer \& Jerusalem, 2003). Sample item: "I can always manage to solve difficult problems if I try hard enough." The range of options of answers reaches from $1=$ strongly agree to $5=$ strongly disagree. The given answers get summed up $(\min =10$; $\max =40)$. A low score (10) equates a high level of self efficacy on the contrary a high score (34+) corresponds a low level of self efficacy. The internal consistency is 0.76 to .90 , with the majority in the high 0.80 s (Schwarzer \& Jerusalem, 2003).

6) Emotional Intelligence. The Trait Emotional Intelligence Questionnaire-Short Form-questionnaire (TEIQue-SF) by Cooper \& Petrides (2010) contains 30 items and is designed to measure global trait emotional intelligence. "Trait emotional intelligence refers to a constellation of emotional self-perceptions located at the lower levels of personality hierarchies" (Cooper and Petrides, 2010). Answers were given by a scale from 1-strongly agree to 7 strongly disagree. The given answers get summed up $(\min =30 ; \max =270) . M=160$ and $S D=$ 19.4. The higher the score, the better the Emotional Intelligence and the other way round. The EI can be measured through self-report items like: "I'm good at understanding the way other people feel." "At the global level, the TEIQue-SF showed very good precision across most of the latent trait range" (Cooper \& Petrides, 2010).

7) Demographics. A dedicated questionnaire was used to collect background information regarding the participants' gender, Socio economic status, age, religious affiliation and so on.

\subsection{Procedure and Ethical Considerations}

The study was approved by the university's IRB. Data was collected using a nonidentifying entrance into an online survey. Students were briefed that their choice whether to participate or not will have no bearing on their grades or assessments. Data provided was kept anonymous from the moment students entered 
the information. All the participants were approached within the time frame of two large introductory classes help by the same faculty member.

\section{Results}

\subsection{Descriptive Statistics}

Before testing the study model, the main variables included in the analyses were examined for normality, internal consistency and distribution coefficients. These analyses are summarized in Table 1 presented below.

We next examined the preliminary associations between the study variables using a Pearson correlation matrix, presented herein. See Table 2, next page for details.

The correlation matrix provides some support to our hypothesized model: Individual resources correlate among themselves and between them and social support. Of the demographics, only gender showed significant associations with any of the individual resources and therefore is the only demographic included in the analyses.

\subsection{Model Testing}

We next tested the full model using AMOS 20.0, to run a path analysis. While the full model (see Figure 1) was not fully supported by the original analysis, omitting the non-significant paths provided an empirical model well-fitting the data, as described in Figure 2, next page.

The results portray a double mediation model in which gender and being a FGS associate with lower levels of individual resources which in then associate with social support which then associates (along with gender) with students' GPA. This tiered model supports the possibility that individual resources facilitate the recruitment and use of social support and perhaps other related social resources to better cope with academic challenges.

\section{Discussion}

FGS are documented to show higher levels of difficulty in coping with the

Table 1. Descriptive statistics for the study variables $(n=199)$.

\begin{tabular}{cccccc}
\hline & Social support & SOC & Grit & SE & EI \\
\hline Mean & 1.951 & 43.256 & 4.625 & 21.889 & 154.693 \\
Std. Deviation & 0.693 & 6.169 & 0.530 & 4.005 & 18.065 \\
Skewness & 0.747 & -0.561 & -0.408 & 0.176 & -0.570 \\
Std. Error of Skewness & 0.172 & 0.172 & 0.172 & 0.172 & 0.172 \\
Kurtosis & 0.115 & 0.734 & -0.088 & 0.431 & 0.176 \\
Std. Error of Kurtosis & 0.343 & 0.343 & 0.343 & 0.343 & 0.343 \\
Minimum & 1.000 & 20.000 & 3.000 & 10.000 & 91.000 \\
Maximum & 4.250 & 58.000 & 5.917 & 34.000 & 190.000 \\
\hline
\end{tabular}


Table 2. Correlation results.

\begin{tabular}{|c|c|c|c|c|c|c|c|c|c|c|c|c|c|}
\hline Variable & gender & & FGS & & $\mathrm{AP}$ & SoSu & & Soc & & Grit & & SE & TEIQ_SF \\
\hline 1.t_Gender & - & & & & & & & & & & & & \\
\hline 2. FGS & 0.033 & & - & & & & & & & & & & \\
\hline 3. AP & -0.114 & & -0.028 & & - & & & & & & & & \\
\hline 4. Summe_SoSu & -0.118 & & 0.030 & & 0.101 & - & & & & & & & \\
\hline 5. Summe_Soc & 0.128 & & -0.178 & & -0.095 & -0.355 & $* * *$ & - & & & & & \\
\hline 6. Summe_Grit & 0.169 & * & -0.192 & * & -0.048 & -0.111 & & 0.392 & $* * *$ & - & & & \\
\hline 7. Summe_SE & -0.060 & & 0.084 & & 0.005 & 0.232 & $* * *$ & -0.476 & $* * *$ & -0.357 & $* * *$ & - & \\
\hline 8. Summe_TEIQ_SF & 0.181 & * & -0.079 & & -0.110 & -0.406 & $* * *$ & 0.690 & $* * *$ & 0.445 & $* * *$ & $-0.595 * * *$ & - \\
\hline
\end{tabular}

${ }^{*} p<0.05,{ }^{* *} p<0.01,{ }^{* * *} p<0.001$.

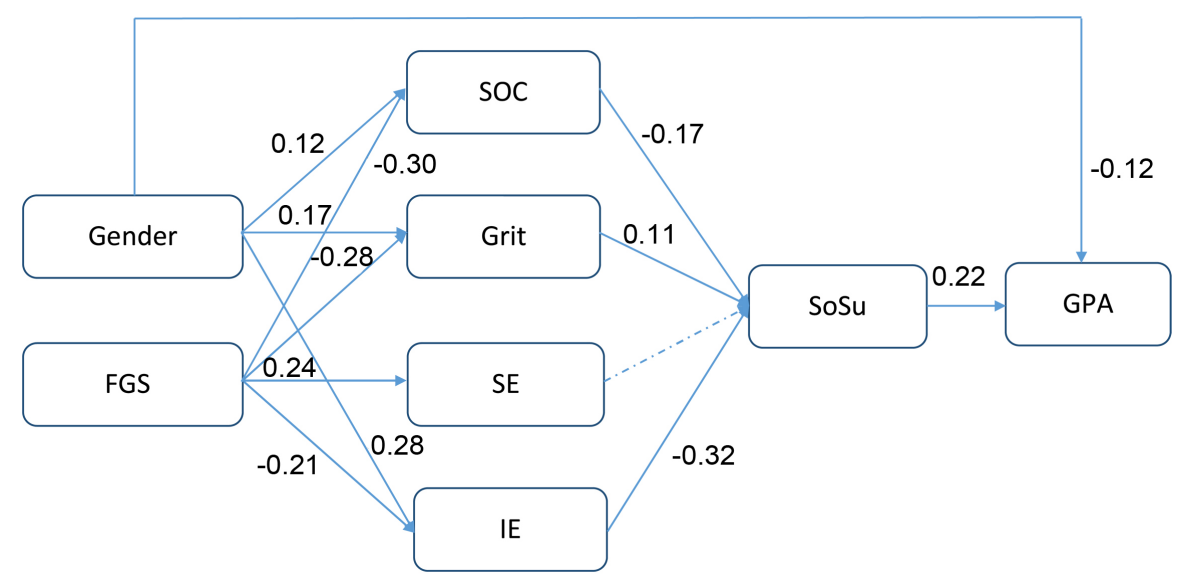

Figure 2. The empirical model results of the path analyses. FGS: First Generation student; SOC: Sense of Coherence; SE: Self efficacy; EI: Emotional Intelligence; SOSU = Social Support; GPA $=$ Grand Point Average. Chi Square $=57.32 ; \mathrm{df}=11 p<0.01 . \mathrm{CFI}=0.94$ $\mathrm{NFI}=0.93$ RMSEA $=0.05$.

demands of academia and attain lower grades in college compared with their peer hailing from academic families. While the literature is rich with evidence of factors associated with this gap, no comprehensive process-model has been offered or tested within this context so far. This study proposed a model based on major concepts borrowed from the growing field of positive psychology. The model involves three tiers of factors: demographics, personal resources, and social support as a path of interactions between personal and social resources leading to academic attainment.

\subsection{Theoretical vs. the Empirical Models}

The results obtained in a sample of 199 German college students provided support to the model, with slight alterations: of all the background and demographic variables, only gender played a role alongside being FGS as an exogenic factor in the models. While gender showed association already reported in the literature with our main model variables (e.g.: Reiff et al., 2001; Lundström et al., 2019), being FGS associated negatively with all individual resources (including with SE 
which was reverse scored) which in term associated with social support. Eventually Social support showed a positive association with GPA. This path suggests that FGS may be at a disadvantage since they arrive on campus with lower levels of psychological capital-the resources required to cope with a demanding social environment (Luthans et al., 2010). The model also highlights the way these personal resources may work to determine the participants' performance in college: these resources associate with perceived social support which emerges from the model as a pivotal resource related to college related performance. The importance of social support in understanding human coping and adaptation is well documented throughout long years of theory development and research (Malecki \& Demaray, 2006; Mishra, 2020). No wonder then that it may serve as a compensating factor for students who arrive on campus with less knowledge of "the system" than others who had academic experience in their families.

\subsection{Theoretical Contribution}

Theoretically our findings add to the literature examining the role of positive psychology in general and emotional resources in particular within a context that is often viewed as, cognitive' in nature. The model we propose underlines the relevance of emotional and social factors in higher education environments (Gilar-Corbi et al., 2020; Jaeger \& Eagan, 2007). It also suggests a conceptual link between individual level emotional factors and social level behavior and resources (at least at the perceived level). While none of these findings is new, their combination and the successive path they create in our model add to our understanding of how individual recruit and mobilize resources to successfully mitigate challenges in academia and how previous exposure and support may engender these processes.

Our model suggests that personal resources serve as the basis for social support which in turn is one of the strongest factors associated with coping with challenges, including academic and social challenges (MacKinnon, 2012). While the literature on the theoretical role of personal level and individual level resources is somewhat divided, this study supports a model in which individuals level resources allow gathering and recruiting social resources which in turn translate into performance.

\subsection{Implications for Practice}

The model supported in this study may also inform practitioners as they search for ways to empower FGS and ease their transition into academic studies: While personal resources such as SOC, EI, SE and grit build up and form through the lifespan, there is some evidence that targeted interventions may result in better skills resulting from these resources (see for example: Betz \& Schifano, 2000; Kaur, 2011).

An additional way to intervene with FGS resulting from our model is through social support-as academic institutions can form various support groups (like peer-to-peer mentoring), access to counselors and other means of increasing so- 
cial support-which should, in particular, have a gender-specific and intersectionality-sensitive perspective-which seems to play an important role in our path associating being a FGS with academic attainment. College and university counselors and equal opportunity/retention officers may use our model as a basis for targeted interventions with FGS to reduce attrition and enhance achievement and performance of this important yet volatile body of students.

\subsection{Study Limitations}

A few aspects of this study need to be addressed in order to better understand the extent to which our findings may be generalized in varying contexts: Our sample, while adequate in terms of statistical power is limited to a single institution in a single educational setting. Additional contexts and more varied samples may allow better generalization of the model. While we used standardized, validated measures in this study they were all self report format, known to be marred with biases that might undermine internal validity (Donaldson \& Grant-Vallone, 2002). Using test format measures, observational measures, and more diverse measures of academic performance may add to the validity of our results.

\subsection{Directions for Future Studies}

The study model, while accounting and validating directions documented and studied before, may also direct future studies based on questions left unanswered. Thus the role of Gender is highlighted by this model and it seems to work in a complex manner that should be further explored. The double-mediation model may indeed offer some insight into how personal resources help us adapt and effectively cope with challenges, but it only gives us a peek into what seems like a complex conceptual inter-correlations and interactions that need to be further explored. The model proposed and tested here is provides insight into one possible path associating being a FGS and academic attainment, as additional factors and sources for hardship alongside resources for more effective coping still remain to be explored.

\section{Conflicts of Interest}

The authors declare no conflicts of interest regarding the publication of this paper.

\section{References}

Agustiani, H., Cahyad, S., \& Musa, M. (2016). Self-Efficacy and Self-Regulated Learning as Predictors of Students' Academic Performance. Open Psychology Journal, 9, 1-6. https://doi.org/10.2174/1874350101609010001

Alvarado, A., Spatariu, A., \& Woodbury, C. (2017). Resilience \& Emotional Intelligence between First Generation College Students and Non-First Generation College Students. FOCUS on Colleges, Universities \& Schools, 11, 1-10.

Antonovsky, A. (1996). The Salutogenic Model as a Theory to Guide Health Promotion. Health Promotion International, 11, 11-18. https://doi.org/10.1093/heapro/11.1.11 
Armstrong, A. R., Galligan, R. F., \& Critchley, C. R. (2011). Emotional Intelligence and Psychological Resilience to Negative Life Events. Personality and Individual Differences, 51, 331-336. https://doi.org/10.1016/j.paid.2011.03.025

Artino Jr., A. R. (2012). Academic Self-Efficacy: From Educational Theory to Instructional Practice. Perspectives on Medical Education, 1, 76-85. https://doi.org/10.1007/s40037-012-0012-5

Aspelmeier, J. E., Love, M. M., McGill, L. A., Elliott, A. N., \& Pierce, T. W. (2012). SelfEsteem, Locus of Control, College Adjustment, and GPA among First- and Continuing-Generation Students: A Moderator Model of Generational Status. Research in Higher Education, 53, 755-781. https://doi.org/10.1007/s11162-011-9252-1

Aymans, S. C., \& Kauffeld, S. (2015). To Leave or Not to Leave? Critical Factors for University Dropout among First-Generation Students. Zeitschrift Für Hochschulentwicklung, 10, 23-43. https://doi.org/10.3217/zfhe-10-04/02

Azhar, M., Nadeem, S., Naz, F., Perveen, F., \& Sameen, A. (2014). Impact of Parental Education and Socio-Economic Status on Academic Achievements of University Students. European Journal of Psychological Research, 1, 1-9.

Betz, N. E., \& Schifano, R. S. (2000). Evaluation of an Intervention to Increase Realistic Self-Efficacy and Interests in College Women. Journal of Vocational Behavior, 56, 35-52. https://doi.org/10.1006/jvbe.1999.1690

Bouffard-Bouchard, T. (1990). Influence of Self-Efficacy on Performance in a Cognitive Task. Journal of Social Psychology, 130, 353-363. https://doi.org/10.1080/00224545.1990.9924591

Cooper, A., \& Petrides, K. V. (2010). A Psychometric Analysis of the Trait Emotional Intelligence Questionnaire-Short Form (TEIQue-SF) Using Item Response Theory. Journal of Personality Assessment, 92, 449-457. https://doi.org/10.1080/00223891.2010.497426

Donaldson, S. I., \& Grant-Vallone, E. J. (2002). Understanding Self-Report Bias in Organizational Behavior Research. Journal of Business and Psychology, 17, 245-260. https://doi.org/10.1023/A:1019637632584

Duckworth, A. L., Peterson, C., Matthews, M. D., \& Kelly, D. R. (2007). Grit: Perseverance and Passion for Long-Term Goals. Journal of Personality and Social Psychology 92, 1087-1101. https://doi.org/10.1037/0022-3514.92.6.1087

Duckworth, A., \& Quinn, P.D. (2009). Development and Validation of the Short Grit Scale(Grit-S). Journal of Personality Assessment, 91, 166-174. https://doi.org/10.1080/00223890802634290

Fiscella, K., \& Kitzman, H. (2009). Disparities in Academic Achievement and Health: The Intersection of Child Education and Health Policy. Pediatrics, 123, 1073-1080. https://doi.org/10.1542/peds.2008-0533

Fischer, A. H., Kret, M. E., \& Broekens, J. (2018). Gender Differences in Emotion Perception and Self-Reported Emotional Intelligence: A Test of the Emotion Sensitivity Hypothesis. PLoS ONE, 13, Article ID: e0190712. https://doi.org/10.1371/journal.pone.0190712

Fleckenstein, J., Schmidt, F. T. C., \& Möller, J. (2014). Wer hat Biss? Beharrlichkeit und beständiges Interesse von Lehramtsstudierenden. Eine deutsche Adaptation der 12-Item Grit Scale. Psychologie in Erziehung und Unterricht, 61, 281.

https://doi.org/10.2378/peu2014.art22d

Gilar-Corbi, R., Pozo-Rico, T., Castejón, J. L., Sánchez, T., Sandoval-Palis, I., \& Vidal, J. (2020). Academic Achievement and Failure in University Studies: Motivational and Emotional Factors. Sustainability, 12, Article No. 9798. 
https://doi.org/10.3390/su12239798

Haveman, R., \& Smeeding, T. (2006). The Role of Higher Education in Social Mobility. The Future of Children, 16, 125-150. https://doi.org/10.1353/foc.2006.0015

Jaeger, A. J., \& Eagan, M. K. (2007). Exploring the Value of Emotional Intelligence: A Means to Improve Academic Performance. Journal of Student Affairs Research and Practice, 44, 910-935. https://doi.org/10.2202/0027-6014.1834

Kaur, T. (2011). A Study of Impact of Life Skills Intervention Training on Emotional Intelligence of College Adolescents. Indian Journal of Psychological Science, 2, 112-125.

Le Masson, V., Lovell, E., \& Pichon, F. (2016, January 21). Gender and Resilience: From Theory to Practice. BRACED Knowledge Manager.

https://www.odi.org/publications/9967-gender-and-resilience-theory-practice

Lundström, S., Jormfeldt, H., Ahlström, B. H., \& Skärsäter, I. (2019). Health-Related Lifestyle and Perceived Health among People with Severe Mental Illness: Gender Differences and Degree of Sense of Coherence. Archives of Psychiatric Nursing, 33, 182-188. https://doi.org/10.1016/j.apnu.2018.12.002

Luthans, F., Avey, J. B., Avolio, B. J., \& Peterson, S. J. (2010). The Development and Resulting Performance Impact of Positive Psychological Capital. Human Resource Development Quarterly, 21, 41-67. https://doi.org/10.1002/hrdq.20034

MacCann, C., Fogarty, G. J., Zeidner, M., \& Roberts, R. D. (2011). Coping Mediates the Relationship between Emotional Intelligence (EI) and Academic Achievement. Contemporary Educational Psychology, 36, 60-70.

https://doi.org/10.1016/j.cedpsych.2010.11.002

MacKinnon, S. P. (2012). Perceived Social Support and Academic Achievement: CrossLagged Panel and Bivariate Growth Curve Analyses. Journal of Youth and Adolescence, 41, 474-485. https://doi.org/10.1007/s10964-011-9691-1

Malecki, C. K., \& Demaray, M. K. (2006). Social Support as a Buffer in the Relationship between Socioeconomic Status and Academic Performance. School Psychology Quarterly, 21, 375-395. https://doi.org/10.1037/h0084129

Mishra, S. (2020). Social Networks, Social Capital, Social Support and Academic Success in Higher Education: A Systematic Review with a Special Focus on 'Underrepresented' Students. Educational Research Review, 29, Article ID: 100307.

https://doi.org/10.1016/j.edurev.2019.100307

Multon, K. D., Brown, S. D., \& Lent, R. W. (1991). Relation of Self-Efficacy Beliefs to Academic Outcomes: A Meta-Analytic Investigation. Journal of Counseling Psychology, 38, 30-38. https://doi.org/10.1037/0022-0167.38.1.30

Nasir, M., \& Iqbal, S. (2019). Academic Self Efficacy as a Predictor of Academic Achievement of Students in Pre Service Teacher Training Programs. Bulletin of Education and Research, 41, 33-42.

Niemivirta, M., \& Tapola, A. (2007). Self-Efficacy, Interest, and Task Performance: Within-Task Changes, Mutual Relationships, and Predictive Effect. Zeitschrift für Pädagogische Psychologie, 21, 241-250. https://doi.org/10.1024/1010-0652.21.3.241

Ouweneel, E., Le Blanc, P. M., \& Schaufeli, W. B. (2011). Flourishing Students: A Longitudinal Study on Positive Emotions, Personal Resources, and Study Engagement. The Journal of Positive Psychology, 6, 142-153. https://doi.org/10.1080/17439760.2011.558847

Ouweneel, E., Schaufeli, W. B., \& Blanc, P. M. (2013). Believe, and You Will Achieve: Changes over Time in Self-Efficacy, Engagement, and Performance. Applied Psychology: Health and Well-Being, 5, 225-247. https://doi.org/10.1111/aphw.12008 
Palbusa, J. A., \& Gauvain, M. (2017). Parent-Student Communication about College and Freshman Grades in First-Generation and Non-First-Generation Students. Journal of College Student Development, 58, 107-112. https://doi.org/10.1353/csd.2017.0007

Park, C. L., Cohen, L. H., \& Murch, R. L. (1996). Assessment and Prediction of StressRelated Growth. Journal of Personality, 64, 71-105. https://doi.org/10.1111/j.1467-6494.1996.tb00815.x

Pascarella, E. T., Pierson, C. T., Wolniak, G. C., \& Terenzini, P. T. (2004). First-Generation College Students: Additional Evidence on College Experiences and Outcomes. The Journal of Higher Education, 75, 249-284. https://doi.org/10.1080/00221546.2004.11772256

Ramos-Sánchez, L., \& Nichols, L. (2007). Self-Efficacy of First-Generation and NonFirst-Generation College Students: The Relationship with Academic Performance and College Adjustment. Journal of College Counseling, 10, 6-18. https://doi.org/10.1002/j.2161-1882.2007.tb00002.x

Reiff, H. B., Hatzes, N. M., Bramel, M. H., \& Gibbon, T. (2001). The Relation of LD and Gender with Emotional Intelligence in College Students. Journal of Learning Disabilities, 34, 66-78. https://doi.org/10.1177/002221940103400106

Reinelt, E., Barnow, S., Stopsack, M., Aldinger, M., Schmidt, C. O., John, U. et al. (2015). Social Support and the Serotonin Transporter Genotype (5-HTTLPR) Moderate Levels of Resilience, Sense of Coherence, and Depression. American Journal of Medical Genetics Part B: Neuropsychiatric Genetics, 168, 383-391.

https://doi.org/10.1002/ajmg.b.32322

Reynolds, J., \& Cruise, S. (2020). Factors That Influence Persistence among Undergraduate Students: An Analysis of the Impact of Socioeconomic Status and First-Generation Students. Interchange, 51, 199-206. https://doi.org/10.1007/s10780-020-09408-y

Salamonson, Y., Ramjan, L. M., van den Nieuwenhuizen, S., Metcalfe, L., Chang, S., \& Everett, B. (2016). Sense of Coherence, Self-Regulated Learning and Academic Performance in First Year Nursing Students: A Cluster Analysis Approach. Nurse Education in Practice, 17, 208-213. https://doi.org/10.1016/j.nepr.2016.01.001

Schumacher, J., Wilz, G., Gunzelmann, T., \& Brähler, E. (2000). Die Sense of Coherence Scale von Antonovsky. Teststatistische Uberprüfung in einer repräsentativen Bevölkerungsstichprobe und Konstruktion einer Kurzskala. Psychotherapie, Psychosomatik, Medizinische Psychologie, 50, 472-482. https://doi.org/10.1055/s-2000-9207

Schwartz, S. E., Kanchewa, S. S., Rhodes, J. E., Gowdy, G., Stark, A. M., Horn, J. P. et al. (2018). "I'm Having a Little Struggle with This, Can You Help Me Out?": Examining Impacts and Processes of a Social Capital Intervention for First-Generation College Students. American Journal of Community Psychology, 61, 166-178. https://doi.org/10.1002/ajcp.12206

Schwarzer, R., \& Jerusalem, M. (2003). SWE. Skala zur Allgemeinen Selbstwirksamkeitserwartung [Verfahrensdokumentation, Autorenbeschreibung und Fragebogen]. In Leibniz-Institut für Psychologie (ZPID) (Hrsg.), Open Test Archive. Leibniz-Institut für Psychologie.

Schwarzer, R., \& Jerusalem, M. (Hrsg.) (1999). Skalen zur Erfassung von Lehrer-und Schülermerkmalen. Dokumentation der psychometrischen Verfahren im Rahmen der Wissenschaftlichen Begleitung des Modellversuchs Selbstwirksame Schulen. Freie Universität Berlin.

Shankland, R., Kotsou, I., Vallet, F., Bouteyre, E., Dantzer, C., \& Leys, C. (2019) Burnout in University Students: The Mediating Role of Sense of Coherence on the Relationship between Daily Hassles and Burnout. High Education, 78, 91-113.

https://doi.org/10.1007/s10734-018-0332-4 
Strayhorn, T. L. (2007). Factors Influencing the Academic Achievement of First-Generation College Students. Journal of Student Affairs Research and Practice, 43, 12781307. https://doi.org/10.2202/0027-6014.1724

Stuart, M. (2012). Social Mobility and Higher Education: The Life Experiences of First Generation Entrants in Higher Education. Trentham Books Ltd.

Thomas, C. L., Cassady, J. C., \& Heller, M. L. (2017). The Influence of Emotional Intelligence, Cognitive Test Anxiety, and Coping Strategies on Undergraduate Academic Performance. Learning and Individual Differences, 55, 40-48.

https://doi.org/10.1016/j.lindif.2017.03.001

Vallerand, R. J., Houlfort, N., \& Forest, J. (2014). Passion for Work: Determinants and Outcomes. In M. Gagne (Ed.), Oxford Handbook of Work Engagement, Motivation, and Self-Determination Theory (pp. 85-105). Oxford University Press.

York-Anderson, D. C., \& Bowman, S. L. (1991). Assessing the College Knowledge of FirstGeneration and Second-Generation College Students. Journal of College Student Development, 32, 116-122.

Yuh, J., \& Choi, S. (2017). Sources of Social Support, Job Satisfaction, and Quality of Life among Childcare Teachers. The Social Science Journal, 54, 450-457.

https://doi.org/10.1016/j.soscij.2017.08.002 